ISSN 1817-3721, E-ISSN 1818-8745

Plant Tissue Cult. \& Biotech. 28(2): 215-222, 2018 (December)

CBangladesh Assoc. for Plant Tissue Culture \& Biotechnology

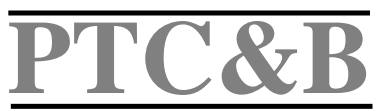

\title{
Indirect in vitro Regeneration of Viola canescens Wall. ex, Roxb. by using Leaf Calli
}

\author{
Arun Kumar Khajuria* and N.S. Bisht \\ Department of Botany, Plant Tissue Culture Laboratory, HNB Garhwal University \\ Campus Pauri, Pauri (Garhwal)-246001, Uttarakhand, India
}

Key words: Viola canescens, Callus, Plant regeneration

\begin{abstract}
An efficient indirect plant regeneration protocol was developed for Viola canescens, an important medicinal herb used in broad spectra of diseases in number of folk medicines since aeon. Excessive use of this plant without any rehabilitating measure has led to decline its natural population. Present investigation reports the use of zeatin to regenerate the plant from the callus on MS following its acclimatization on the soil condition. Calli of the plant responded positively to zeatin and maximum number of shoots $13.07 \pm 2.01$ were obtained when $9.12 \mu \mathrm{M}$ concentration of zeatin was used. Regenerated shoots were subsequently rooted with IBA on MS and half strength MS and showed maximum number of roots $14.13 \pm 1.64$ after 60 days when medium was fortified with $4.92 \mu \mathrm{M}$ IBA, followed by transferring them to soil condition, acclimatization of the plantlet was carried in growth chamber and then finally to the field for their survival where it showed $80 \%$ survival.
\end{abstract}

\section{Introduction}

Viola canescens Wall. ex, Roxb., one of the important species of violet, commonly known as Himalayan white violet/Banfasa is perennial herb of Violaceae. Plant is traditionally used in number of ethanomedical preparations and used to cure cough, cold, fever, jaundice, dysentery, malaria, several nervous disorders, antiseptic in case of dermatogens problems and also given as anti-cancerous drug (Hamayun et al. 2006, Rana et al. 2010, Abbasi et al. 2010, Adnan et al. 2010, Hussain et al. 2011, Rana et al. 2014). The plant was investigated for number of activities and it has been found that solvent extract of Viola canescens has

*Author for correspondence: <arun.khajuria20@gmail.com>

DOI: https://doi.org/10.3329/ptcb.v28i2.39680 
antioxidant, hepatoprotective activity (Abdullah et al. 2017), antibacterial (Dwarika Prasad 2014), antifungal (Rawal et al. 2015) and antimalarial activity (Verma et al. 2011). Zinc based nanoparticles showed antimicrobial activities against Staphylococcus aureus and E. coli (Khajuria et al. 2017a), Due to high demand among the locals and at National/International levels coupled with its heavy indiscriminate collection from wild, this plant is rapidly disappearing from their natural habitat as observed at Swat valley of Azad Kashmir (Hamayun et al. 2006), Malam jabba valley of Swat Pakistan etc. Further, micropropagation offers an alternative and profitable technique to overcome the high demand of the medicinal plants by providing disease free superior quality, identical plant material in faster rate without affecting its natural habitat throughout the year. Hence, there is need to carry out tissue culture work for mass multiplication and conservation of this plant to fill the gap between demand and supply for commercial use. Micropropagtion work on other species of Viola viz and Viola pilosa ( Soni and Kour 2013), Viola ordoata (Naeem et al. 2013), Viola uliginosa (Slazak et al. 2015), Viola patrinii (Chalageri and Babu 2012) has been reported but no work on this species has been reported so far. So it was aimed to develop an effective protocol for plant regeneration of Viola canescens.

\section{Materials and Methods}

Healthy plants of Viola canescens were collected from its natural habitat of Nag dev forest range Pauri, Pauri (Garhwal), Uttarakhand, India. Initially explants were rinsed with luke warm water with 2 - 3 drops of liquid soap with constant stirring for $10 \mathrm{~min}$, followed by adding 2 drops of Tween-20 and again stir for 5 min and finally wash under running tap water for $15 \mathrm{~min}$. The surface sterilization of plants was carried out under laminar air chamber, $0.1 \%$ mercury chloride solution $\mathrm{w} / \mathrm{N}$ was used for $90 \mathrm{sec}$ and then washed repeatedly with double distilled autoclaved water for 3 times. Sterilized explants were then blotted dry and trimmed with the help of scalpel and inoculate in callus inducing medium for calli initiation in the explants (Khajuria et al. 2017b). Four to 5 weeks calli were used as mother source for regenerating shoots in Viola canescens. Calli were inoculated on to the MS fortified with different concentrations of zeatin and zeatin + NAA in combinations. The following three parameters were studied during the work i.e., shooting percentage, number of petiole, length of regenerated petioles. Regenerated $2-3 \mathrm{~cm}$ long shoots were transferred to MS and half strength MS fortified with different concentrations of IBA for rhizogenesis responses (root number and root length) and medium without growth regulators was treated as control. Finally, completely developed plantlets 
were placed in growth chambers for acclimatizing before transferring them to soil condition.

During the entire study, MS supplemented with 3\% sucrose $(\mathrm{w} / \mathrm{N})$ and $0.8 \%$ agar $(\mathrm{w} / \mathrm{N})$ was used for callus induction and shoot regeneration from callus. Besides, MS and half strength MS was used for rhizogenesis studies. The $\mathrm{pH}$ of the medium was adjusted to $5.8 \pm 0.2$ prior to an autoclave. All cultures were maintained at $25 \pm 2^{\circ} \mathrm{C}$ and $16-8 \mathrm{hrs}$, temperature and photoperiod, respectively the humidity of the culture room was maintained to $60-70 \%$. Each experiment was repeated thrice with 5-10 replicates each time. All the experiments were repeated thrice and the effect of different treatments was analyzed using oneway (ANOVA), and their means were compared using the Post-hoc Tukey test at the 0.01 and $0.05 \%$ level of significance as shown in Table 4 . Correlation analysis was also calculated.

\section{Results and Discussion}

In order to obtain callus for indirect regeneration of plantlets in Viola. Leaves were used as organ of choice, young leaves of plant were collected from their wild habitat without harming the plants. The leaves were surface sterilized before inoculating in the callus induction medium i.e., fortified with different concentrations of IBA, IBA $+\mathrm{Kn}$ and $\mathrm{Kn}$ alone. The explants showed swelling after 4 - 5 days followed by development of micro calli from their cut ends or from the lower end of the explants, which start appearing after 8 - 11 days of inoculation (Fig A). MS without hormones was used as a control and no calli was observed in control cultures (Table 1), maximum calli induction frequency and best calli proliferation was recorded when MS was supplemented 7.38:6.97 $\mu \mathrm{M}$ concentration of IBA : Kn (Table 2). Four-five weak old calli were used for study dideferentaion and morphogenesis responses using various concentrations of zeatin $(4.92-22.80 \mu \mathrm{M})$ alone or in combination with auxin $2.68 \mu \mathrm{M}$. Inoculated parenchymatous calli passed through different phases before producing shoots, $100 \%$ shooting responses were observed when calli were inoculated on MS fortified with $9.12-22.80 \mu \mathrm{M}$ concentrations of zeatin only $4.92 \mu \mathrm{M}$ concentrations responded $60 \%$ shooting, While the shooting percentage decreases when zeatin : NAA combination was tried (Table 3), which was contrary to number of other workers but in correlation with the work on Tylophora indica by Faisal and Anis (2003). It was further observed that shoots did not directly proliferate from the calli but calli first transformed into shooting buds from which new bunches of shoots (petioles) arises (Fig B). Morphogenetic response in calli showed that maximum average number of shooting buds $(8.6 \pm$ 
1.42) and maximum number of petioles $(13.07 \pm 2.01)$ were recorded in MS fortified with $9.12 \mu \mathrm{M}$ of zeatin.

In another set of experiment another growth factor i.e., "length of regenerated petioles" was also studied, maximum average length $(4.98 \pm 0.64)$ of petioles were recorded in those medium which were fortified with $13.68+2.68$ $\mu \mathrm{M}$ concentration of Zeatin + NAA (Fig. D), while $4.92 \pm 0.64 \mathrm{~cm}$ average length was recorded when culture medium supplemented with $9.12+2.68 \mu \mathrm{M}$ (zeatin + NAA). Higher concentrations of zeatin were found to be less favorable for growth of petiole in the present study.
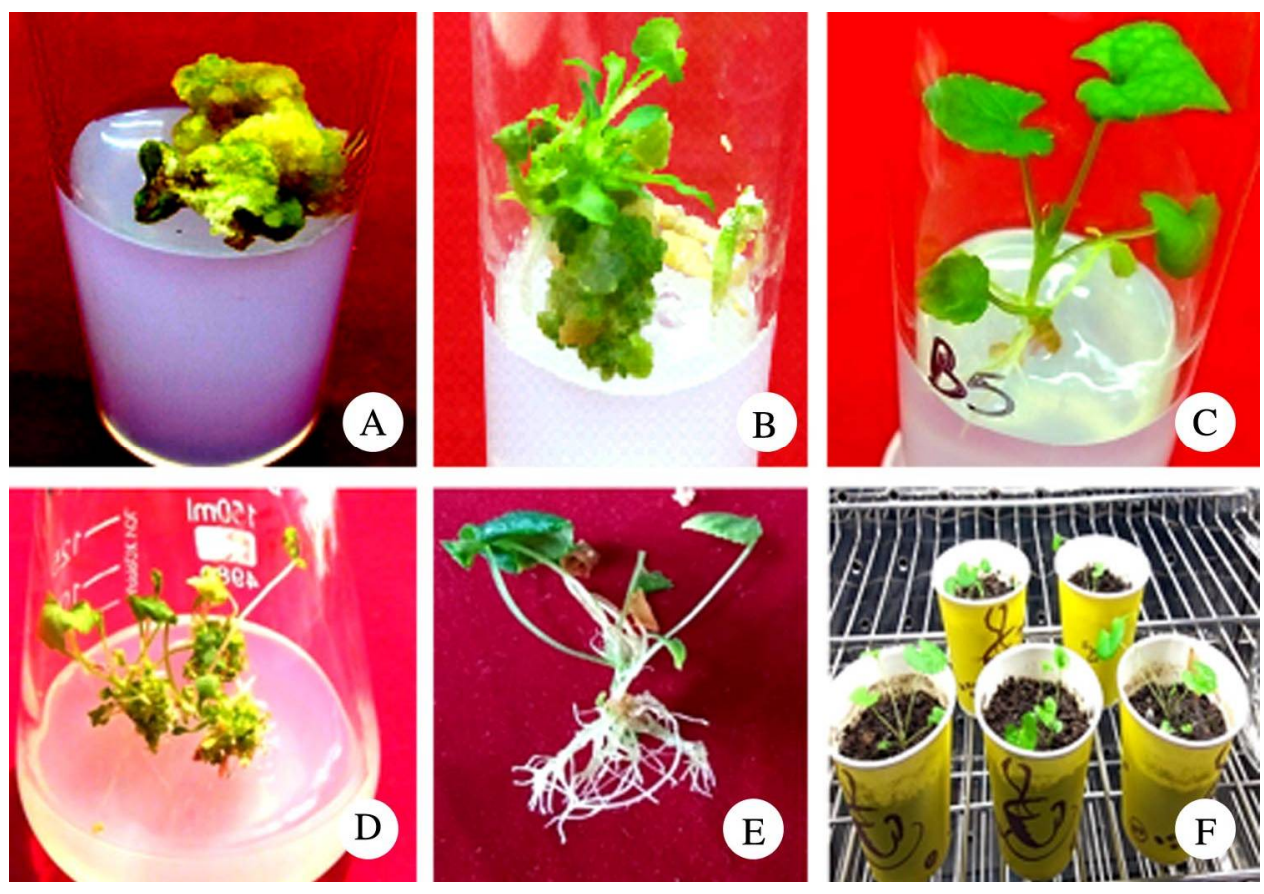

Fig. 1A-F. Indirect in vitro regeneration of Viola canescens. A. Leaf explant inoculated on callus induction medium. B - D. Shoot proliferation from callus. E. Well established complete plant of Viola canescens. F. Well established in vitro plant transferred to paper cups.

For rhizogenesis, 2.0 to $2.5 \mathrm{~cm}$ long shoots were inoculated on MS and half strength MS fortified with 2.46 and $4.92 \mu \mathrm{M}$ of IBA. Maximum root induction (75\%) was noticed when half strength MS was fortified with $4.92 \mu \mathrm{M}$. Initially, the root number was recorded to be $6.27 \pm 1.65$ and $6.63 \pm 2.28$ in 2.46 and 4.92 $\mu \mathrm{M}$, respectively after 30 days of inoculation. It was observed that higher concentration of IBA exhibited the faster rate of root with maximum average root 
number was recorded to be $14.13 \pm 1.64$ in $4.92 \mu \mathrm{M}$ IBA. Root length ranged from $1.40 \pm 0.40$ to $1.59 \pm 0.43$ after 30 days of inoculation in $4.92 \mu \mathrm{M}$ and $2.46 \mu \mathrm{M}$ IBA, respectively and the trend remained same for next 15 days but by the end of 60 days it was noticed that the increment in length of roots was faster in $4.92 \mu \mathrm{M}$ IBA than $2.46 \mu \mathrm{M}$ IBA (Table 6). Besides this MS responded poorly and no root induction was reported till the last measuring period. Further, in full MS medium for the both concentrations the results remain inferior than the half strength MS. These results showed that higher concentration of IBA and half strength of MS is required for both root induction and root elongation for this plant.

Table 1. Callogenesis responses for callus induction frequency in leaf explant of Viola canescens on MS with or without growth regulators.

\begin{tabular}{|c|c|c|c|c|c|c|}
\hline \multirow{2}{*}{$\begin{array}{l}\mathrm{Kn} \\
(\mu \mathrm{M})\end{array}$} & \multicolumn{6}{|c|}{ IBA $(\mu \mathrm{M})$} \\
\hline & 0.00 & 4.92 & 7.38 & 9.84 & 12.30 & 14.76 \\
\hline 0.00 & $00.00 \pm 0.00$ & $00.00 \pm 0.00$ & $00.00 \pm 0.00$ & $00.00 \pm 0.00$ & $00.00 \pm 0.00$ & $00.00 \pm 0.00$ \\
\hline 4.64 & $00.00 \pm 0.00$ & $54.17 \pm 0.48$ & $62.50 \pm 0.50$ & $66.67 \pm 0.47$ & $62.50 \pm 0.47$ & $41.67 \pm 0.44$ \\
\hline 6.97 & $06.67 \pm 0.21$ & $62.50 \pm 0.35$ & $95.83 \pm 0.12$ & $83.33 \pm 0.29$ & $83.33 \pm 0.31$ & $54.17 \pm 0.48$ \\
\hline 9.30 & $00.00 \pm 0.00$ & $58.33 \pm 0.47$ & $83.33 \pm 0.39$ & $87.50 \pm 0.27$ & $70.83 \pm 0.45$ & $75.00 \pm 0.44$ \\
\hline 11.62 & $00.00 \pm 0.00$ & $54.17 \pm 0.50$ & $79.17 \pm 0.43$ & $75.00 \pm 0.44$ & $66.67 \pm 0.50$ & $62.50 \pm 0.48$ \\
\hline
\end{tabular}

Callus induction from leaf explants of $V$. canescens (Data pooled from 3 independent experiments, values are mean \pm Sd).

Table 2. Callogenesis responses for calli proliferation in leaf explant of Viola canescens on MS with or without growth regulators.

\begin{tabular}{ccccccc}
\hline $\mathrm{Kn}$ & \multicolumn{7}{c}{$\mathrm{IBA}(\mu \mathrm{M})$} \\
\cline { 2 - 7 }$(\mu \mathrm{M})$ & 0.00 & 4.92 & 7.38 & 9.84 & 12.30 & 14.76 \\
\hline $0.00 \mu \mathrm{M}$ & - & - & - & - & - & - \\
$4.64 \mu \mathrm{M}$ & - & + & + & $+1+$ & ++ & + \\
$6.97 \mu \mathrm{M}$ & - & + & $+1+$ & $+1+$ & $+1+$ & ++ \\
$9.30 \mu \mathrm{M}$ & - & ++ & ++ & $+1+$ & $+1+$ & ++ \\
$11.62 \mu \mathrm{M}$ & - & ++ & ++ & $+1+$ & $+1+$ & ++ \\
\hline
\end{tabular}

- No callus, + Poor, + Good, ++ Better, +11+ Best.

Callus proliferation from leaf explants of $V$. canescens.

ANOVA and Tukey analysis showed that data within group in nonsignificant, but within group highly significant at 0.1 and $0.5 \%$ levels. Correlation between different group effect of different concentrations with growth parameters also showed significance at the 0.01 level (2-tailed). 
Table 3. Effect of different concentrations of zeatin and NAA on calli for regeneration responses of Viola canescens.

\begin{tabular}{cccccc}
\hline $\begin{array}{c}\text { Sl. } \\
\text { No }\end{array}$ & $\begin{array}{c}\text { Conc. of } \\
\text { zeatin } \mu \mathrm{M}\end{array}$ & $\begin{array}{c}\text { \% of culture } \\
\text { showing } \\
\text { shooting }\end{array}$ & $\begin{array}{c}\text { Average no. of } \\
\text { shooting buds }\end{array}$ & $\begin{array}{c}\text { Average no. of } \\
\text { shoots } / \text { buds }\end{array}$ & $\begin{array}{c}\text { Average } \\
\text { length of } \\
\text { shoots }\end{array}$ \\
\hline 1 & 4.56 & 60 & $3.93 \pm 1.06^{\mathrm{a}}$ & $6.13 \pm 1.11^{\mathrm{a}}$ & $3.72 \pm 0.54^{\mathrm{ab}}$ \\
2 & 9.12 & 100 & $8.60 \pm 1.42^{\mathrm{b}}$ & $13.07 \pm 2.01^{\mathrm{b}}$ & $4.38 \pm 0.74^{\mathrm{b}}$ \\
3 & 13.68 & 100 & $4.93 \pm 1.45^{\mathrm{ac}}$ & $8.47 \pm 1.63^{\mathrm{c}}$ & $4.62 \pm 0.85^{\mathrm{bc}}$ \\
4 & 18.24 & 100 & $4.73 \pm 1.85^{\mathrm{acd}}$ & $8.53 \pm 1.83^{\mathrm{cd}}$ & $2.93 \pm 0.59^{\mathrm{ad}}$ \\
5 & 22.8 & 100 & $5.40 \pm 1.92^{\mathrm{acde}}$ & $9.53 \pm 1.76^{\mathrm{cde}}$ & $2.89 \pm 1.20^{\mathrm{de}}$ \\
6 & $4.56 \pm 2.68$ & 40 & $3.33 \pm 1.48^{\mathrm{f}}$ & $4.27 \pm 1.67^{\mathrm{f}}$ & $4.33 \pm 0.55^{\mathrm{f}}$ \\
7 & $9.12 \pm 2.68$ & 85 & $4.87 \pm 1.21^{\mathrm{g}}$ & $6.93 \pm 2.07^{\mathrm{g}}$ & $4.92 \pm 0.64^{\mathrm{g}}$ \\
8 & $13.68 \pm 2.68$ & 65 & $7.67 \pm 2.03^{\mathrm{h}}$ & $8.93 \pm 1.78^{\mathrm{h}}$ & $4.98 \pm 0.62^{\mathrm{fh}}$ \\
\hline
\end{tabular}

Data pooled from 3 independent experiments, Values represent means standard deviation. Values are significantly different by the Tukey test at 0.01 and $0.05 \%$ probability level within column. Values have same letters are non-significant.

Table 4. ANOVA analysis.

\begin{tabular}{llccc}
\hline & & Mean square & F & Sig. \\
\hline Number of & Between groups & 101.620 & 28.698 & 0.000 \\
petiole & Within groups & 3.541 & & \\
Length of & Between groups & 9.632 & 14.550 & 0.000 \\
petiole & Within groups & .662 & & \\
Shooting buds & Between groups & 48.680 & 18.931 & 0.000 \\
& Within groups & 2.571 & & \\
\hline
\end{tabular}

Table 5. Correlation.

\begin{tabular}{lcccc}
\hline & CONC & $\begin{array}{c}\text { Number of } \\
\text { petiole }\end{array}$ & $\begin{array}{c}\text { Length of } \\
\text { petiole }\end{array}$ & $\begin{array}{c}\text { Shooting } \\
\text { buds }\end{array}$ \\
\hline CONC & 1 & & & \\
Number of petiole & 0.134 & 1 & 1 & \\
Length of petiole & $-0.415^{* *}$ & 0.149 & 0.198 & 1 \\
Shooting buds & -0.059 & $0.544^{* *}$ & & \\
\hline
\end{tabular}

**Correlation is significant at the 0.01 level (2-tailed).

The regenerated plantlets were hardened in growth chamber under controlled environmental condition for first three weeks (Fig F). After three weeks plants were placed under diffuse light for a week before exposing to full sun and then finally into the forest condition. Similar results were obtained in 
Bacopa monnieri (Pandiyan and Selvaraj 2012), Centella asiatica (Patra et al. 1998), Artemisia judaica (Liu et al. 2003), Disocorea zingiberensis (Chen et al. 2003), Cardiospermum helicacabum (Thomas and Maseena 2006), Whithania somnifera (Chandran et al. 2007).

Table 6. MS and half MS + IBA for rhizogenesis.

\begin{tabular}{llccccc}
\hline Sl. & Growth & No. of & \multicolumn{4}{c}{ IBA concentrations } \\
\cline { 3 - 7 } No. & parameter & days & $\begin{array}{c}\text { Number of } \\
\text { root }\end{array}$ & \multicolumn{3}{c}{$\begin{array}{c}\text { Length of } \\
\text { root in cm }\end{array}$} \\
\cline { 3 - 7 } & & $2.46 \mu \mathrm{M}$ & $4.92 \mu \mathrm{M}$ & $2.46 \mu \mathrm{M}$ & $4.92 \mu \mathrm{M}$ \\
\hline 1. & $\begin{array}{l}\text { No. and length } \\
\text { of roots (half }\end{array}$ & 30 & $6.27 \pm 1.65$ & $6.63 \pm 2.28$ & $1.59 \pm 0.43$ & $1.40 \pm 0.40$ \\
& 45 & $9.73 \pm 2.59$ & $11.40 \pm 2.54$ & $2.02 \pm 0.39$ & $1.99 \pm 0.40$ \\
& MS) & 60 & $11.30 \pm 2.73$ & $14.13 \pm 1.64$ & $2.69 \pm 0.38$ & $3.67 \pm 0.56$ \\
2. & No. and length & 30 & $\mathrm{NA}$ & $\mathrm{NA}$ & $\mathrm{NA}$ & $\mathrm{NA}$ \\
& of roots (MS) & 45 & $\mathrm{NA}$ & $4.33 \pm 2.59$ & $\mathrm{NA}$ & $2.07 \pm 0.93$ \\
& 60 & $5.83 \pm 3.60$ & $7.27 \pm 2.78$ & $1.72 \pm 0.92$ & $3.07 \pm 1.13$ \\
\hline
\end{tabular}

Data pooled from 3 independent experiments, values represent means standard deviation.

In conclusion, the results confirms the ability of zeatin to transform callus to microshoots effectively and the developed shoots further showed the potency to develop roots when transferred to rooting medium (Fig E). All regenerated plants were similar phenotypically to mother plant. Hence, the investigation yielded a good reliable protocol for large scale multiplication of Viola canescens and at the same time highlights the role of zeatin to transforms calli into multiple shoots, which was the objective of the study.

\section{References}

Abbasi AM, Khan AM, Ahmed M and Zafar M (2010) Herbal medicines used to cure various ailments by the inhabitant of Abbottabad district, North West Frontier Province, Pakistan. Ind. J. Trad. Knowledge 9(1): 175-83.

Adnan M and Hlscher D (2010) Medicinal plant abundance in degraded and reforested sites in Northwest Pakistan. Mountain Res. Dev. 30: 25-32.

Bisht NS and Khajuria AK (2014) Ethno-medicinal plants of Tehsil, Kathua, Jammu \& Kashmir. J. Mount. Res. 9: 1-12.

Chalageri G and Babu UV (2012) In vitro plant regeneration via petiole callus of Viola patriniií and genetic fidelity assessment using RAPD marker. Turk J. Bot. 36: 358-368.

Chandran C Karthikeyan K and Kulothungan S (2007) In vitro propagation of Withania somnifera (L.) Dunal. from shoot tip and nodal explants. J. Scientific Transactions in Environment and Technovation 1(1): 15-18.

Chen Y, Fan J, Yi F, Luo Z and Fu Y (2003) Rapid clonal propagation of Dioscorea zingiberensis. Plant Cell, Tiss. Org. Cult. 73(1): 75-80. 
Faisal M, and Anis, Mohammad (2003) Rapid mass propagation of Tylophora indica Merrill via leaf callus culture, Plant Cell Tissue and Organ Culture 75: 125-129.

Hamayun M, Khan SA, Sohn EY and Lee I (2006) Folk medicinal knowledge and conservation status of some economically valued medicinal plants of District Swat, Pakistan," Lyonia 11(2): 101-113.

Hussain I, Bano A and Ullah F (2011) Traditional drug therapies from various medicinal plants of Central Karakoram National Park, Gilgit-Baltistan, Pakistan, Pak. J. Bot. 43: 79-84.

Khajuria AK, Bisht NS and Kumar G (2017a) Synthesis of Zinc oxide nanoparticles using leaf extract of Viola canescens Wall. ex, Roxb. and their antimicrobial activity. J. Pharmacognosy and Phytochemistry 6(5): 1301-1304.

Khajuria AK, Bisht NS and Krishan R (2017b) Effect of 2,4-D and cytokinins on callus induction in different explants of Viola canescens Wall. ex, Roxb. Plant Archives 17(2): 833-838.

Liu CZ, Murch SJ, El-Demerdash M, and Saxena PK (2004) Artemisia judaica L.: micropropagation and antioxidant activity. Journal of Biotechnology, 110(1): 63-71.

Naeem M, Naveed I, Naqvi SMS and Mahmood T (2013) Standardization of Tissue culture conditions and estimation of free scavenging activity in Viola odorata L. Pak. J. Bot. 45(1):197-202.

Pandiyan P and Selvaraj T (2012) In vitro multiplication of Bacopa monnieri (L.) Pennell from shoot tip and nodal explants. J. Agricultural Technol. 8(3): 1099-1108.

Patra A, Rai B, Rout GR and Das P (1998) Successful plant regeneration from callus cultures of Centella asiatica (Linn.) Urban. Plant Growth Regulation 24(1): 13-16.

Rana CS, Sharma A, Kumar N, Dangwal LR and Tiwari JK (2010) Ethnopharmacology of some important medicinal plants of Nanda Devi National Park (NDNP) Uttarakhand, India, Nature and Science 8(11): 9-14.

Rana PK, Kumar P, Singhal VK and Rana C (2014) Uses of local plant biodiversity among the Tribal community of Pangi Valley of district Chamba in Cold Desert Himalaya, India, The Scientific World J. http://dx.doi.org/10.1155/2014/753289.

Rawal P, Adhikari RS and Tiwari A (2015) Antifungal activity of Viola canescens against Fusarium oxysporum f. sp. Lycopersici. Int. J. Curr. Microbiol. App. Sci 4(5): 1025-1032.

Soni M, and Kour R (2013) Rapid in vitro propagation, conservation and analysis of genetic stability of Viola pilosa. Physiol. Mol. Biol Plants. 20(1): 95-101.

Slazak B, SliwinskaE, Saluga M, Ronikier M, Bugak J, Slomka A, Goranson U and Kuta (2015) Micropropagtion of Viola uliginosa (Violaceae) for endangered species conservation and for somaclonal variation enhanced cyclotide biosynthesis. Plant Cell, Tiss. Org. Cult. 120(1): 170-190.

Thomas TD and Maseena EA (2006) Callus induction and plant regeneration in Cardiospermum helicacabum L. an important medicinal plant. Scientia Horticulturae. 108: 322-326.

Verma G, Dua VK, Agarwal DD and Atul PK (2011) Antimalarial activity of Holarrhena antidysenterica and Viola canescens, plants traditionally used against malaria in the Garhwal region of north-west Himalaya. Malaria Journal 10(20): 2-5. 